\title{
"Ditadura reservada": um olhar psicossocial entre as cenas de uma produção audiovisual
}

\author{
"Reserved dictatorship": a psychosocial look between the scenes of an \\ audio-visual production
}

\section{"Dictadura reservada": una mirada psicosocial entre las escenas de una producción audiovisual}

\author{
Lilian Vegini Baptista $^{\mathrm{a}} \mathbb{D}^{\mathrm{D}}$; Allan Henrique Gomes ${ }^{\mathrm{b}}$ \\ ${ }^{a}$ Mestranda em Educação pela Universidade da Região de Joinville (UNIVILLE). Psicóloga pós-graduada em Psicologia e Práticas \\ Clínicas pela Associação Catarinense de Ensino (ACE). Universidade da Região de Joinville, Joinville, SC, Brasil - E-mail: \\ lilivegini@hotmail.com \\ ${ }^{\mathrm{b}}$ Doutor em Psicologia pela Universidade Federal de Santa Catarina (UFSC). Professor adjunto na Universidade da Região de Joinville \\ (UNIVILLE); integrante do Laboratório de Psicologia Social Comunitária da Associação Catarinense de Ensino (ACE). Universidade \\ da Região de Joinville, Joinville, SC, Brasil - E-mail: allanpsi@yahoo.com.br
}

\begin{abstract}
Resumo: Este artigo apresenta os resultados da investigação do documentário "Ditadura Reservada", que exibe memórias de sujeitos militantes do comunismo em Joinville - SC durante o regime militar (1964-1984). O objetivo desta pesquisa foi realizar leituras daquilo que o documentário nos mostra, especificamente, sobre as relações entre filme e pesquisadores-espectadores, atentando as dimensões estéticas da obra. A composição metodológica foi pautada nas discussões de Vygotsky acerca da estética e nos princípios do paradigma indiciário de Ginzburg. Assistimos a obra inicialmente sem preocupações e sem pesquisar por detalhes a serem analisados; posteriormente foram vistas com a intenção de "ouvir menos e enxergar mais", como uma forma de envolvermo-nos com o documentário para além do verbal. Assim, afirma-se que as minúcias observadas nas entre cenas é que compõem a dimensão estética da obra em questão e que podem gerar leituras e recepções inesgotáveis e variáveis de acordo com cada espectador.
\end{abstract}

Palavras-chave: Ditadura Militar. Audiovisual. Psicologia Social.

\begin{abstract}
This paper presents the research results of the documentary "Reserved Dictatorship", which exhibits the memories of communist militant subjects in Joinville - SC, Brazil during the military regime (1964-1984). The main objective of this work is to look for possible readings of what the documentary shows us specifically about relations between movie and researchers/viewers, paying attention to the work aesthetic dimension. The methodological composition was based on Vygotsky's discussions about the aesthetic and on Carlos Ginzburg's principles of the index paradigm. We watched the work initially without worrying and without researching for details to be analyzed; later they were seen with the intention of "less listening and more seeing" as a way of engaging with the documentary beyond verbal language. Thus, it is stated that the details observed in between scenes compose the aesthetic dimension of the designated work, and they can generate inexhaustible and variable readings and receptions to every viewer.
\end{abstract}

Keywords: Military dictatorship; audiovisual; Social Psychology, 
Resumen: Este artículo presenta los resultados de la investigación del documental "dictadura reservada", que muestra los recuerdos de los militantes comunistas en Joinville - SC, Brasil, durante el régimen militar. El objetivo principal de este trabajo es buscar posibles lecturas de lo que el documental nos muestra específicamente sobre las relaciones entre la película y los investigadores/ espectadores, prestando atención a la dimensión estética del trabajo. La composición metodológica se basó en las discusiones de Vygotsky sobre la estética y en los principios del paradigma del índice de Carlos Ginzburg. Observamos el trabajo inicialmente sin preocuparnos y sin investigar los detalles para analizarlos; más tarde, fueron vistos con la intención de "escuchar menos y ver más" como una forma de involucrarse con el documental más allá del lenguaje verbal. Así, se afirma que las minucias observadas entre las escenas componen la dimensión estética de la obra designada, y pueden generar lecturas y recepciones inagotables y variables para cada espectador.

Palabras clave: Dictadura militar. Audiovisual. Psicología Social.

\section{Como citar o artigo:}

BAPTISTA, L. V. GOMES, A. H. "Ditadura reservada": um olhar psicossocial entre as cenas de uma produção audiovisual. Revista de Ciências Humanas, v.52, 2018. DOI: 10.5007/2178-4582.2018.49129

\section{INTRODUÇÃO}

A Psicologia vem ampliando os seus saberes/fazeres em relação ao campo das imagens, entre as quais se destacam o cinema e o audiovisual (ALVES, 2017; CABRAL, 2008; LOPES et al., 2017; SANTEIRO; SCHUMACHER; SOUZA, 2017; ZANELLA, 2012; JOBIM E SOUZA, 2006). Ao tempo em que nos lançamos nesta área de conhecimento, passamos a compreender um pouco mais sobre os modos como as relações imagéticas constituem as subjetividades, sendo o audiovisual uma destas portas que se abrem para a expansão da Psicologia Social. Esta interação entre as áreas ainda é muito recente e pouco reconhecida, mas através deste trabalho pretendemos participar da pesquisa audiovisual com aqueles que pensam com a ciência psicológica.

O documentário escolhido para ser objeto de estudo é Ditadura Reservada (2011) que conta com a direção e roteiro de Fabrício Porto, montagem e edição de Fábio Porto, Sabrina Elisa na direção de produção e arte. O filme conta com uma pesquisa histórica, realizada por Bruno da Silva e Maikon Duarte, e a trilha sonora é uma contribuição de Albanir Germano. A união destes artistas resultou em uma obra sensível na medida em que resgata a história de ex-presos políticos e por meio disto, aborda experiências com o comunismo e o socialismo na ditadura militar em Joinville.

Algumas produções audiovisuais realizadas em Joinville destacam-se por abordar temáticas relacionadas a história local e/ou regional. Joinville está localizada no litoral norte catarinense, com população estimada em 583 mil habitantes (IBGE, 2018). A cidade tem sua economia voltada para as indústrias de fundição, fabricação de eletrodomésticos e produtos de material plástico e vive, a partir dos anos 70, um aumento populacional significativo, especialmente, em virtude da chegada de novos habitantes por conta das oportunidades de trabalho nas indústrias do setor metal-mecânico (COELHO, 2011). 
O encontro com a obra ocorreu espontaneamente, tendo em vista a participação dos pesquisadores em circuitos culturais e acadêmicos que exibiram o documentário na época de seu lançamento. Todavia, o interesse em desenvolver uma investigação da obra foi mobilizado pelo envolvimento dos pesquisadores com outros projetos relacionadas à história regional e a produção audiovisual local (GOMES; PASQUALOTTO; BAPTISTA, 2016). O ano de 2014 marcou o cinquentenário da Ditadura Militar no Brasil e o filme Ditadura Reservada (2011), ao exibir memórias locais desta experiência nacional, nos aproximou ainda mais desta realidade, tanto nos seus aspectos históricos como também nas formas como esta experiência ditatorial vem sendo tematizada e significada na atualidade. Assim, compreendemos também, que a modalidade audiovisual é uma fonte riquíssima a ser explorada e é considerada por Gutfreind e Rech (2011, p. 136) como "um favorável e vantajoso meio para documentação da memória". E neste caso, a Psicologia Social pode ter relevante contribuição, especialmente, no modo como as memórias são construídas e ainda as ditaduras persistem.

De acordo com Pollak (1989, p.12) “o filme-testemunho e documentário tornou-se um instrumento poderoso para os rearranjos sucessivos da memória coletiva e, através da televisão, da memória nacional", e assim podemos entender o documentário como uma possibilidade de maior amplitude por abordar uma questão de importância nacional e dar ênfase em um viés local.

Esta pesquisa teve como objetivo realizar leituras daquilo que o documentário nos mostra, especificamente, sobre as relações entre filme e pesquisadores-espectadores, atentando as dimensões estéticas da obra. Para fazer isto, privilegiamos o olhar para as cenas que o documentário exibe e seus muitos efeitos. Nesta perspectiva, o foco desta investigação são as relações estéticas mobilizadas no encontro entre obra e pesquisadores/espectadores (RANCIÈRE, 2010a).

Para tanto, é preciso alargar conceitualmente a compreensão do termo estética e, nisto, a obra de Jacques Rancière tem peculiar relevância, pois ele a entende "como modos de percepção e sensibilidade, a maneira pela qual os indivíduos e grupos constroem o mundo" (RANCIÈRE, 2010b, $\mathrm{s} / \mathrm{p}$ ). Portanto, a estética diz respeito ao sensível, e se distancia da noção moderna da estética como uma disciplina associada ao campo da arte, dedicada a designação da beleza e o juízo das coisas da arte, proposta costumeiramente atribuída ao filósofo alemão Alexander Baumgarten (1714-1762). É importante observar que Rancière não cria um novo conceito para o termo "estética". Na verdade, ele faz uma genealogia do conceito, observando que a palavra estética, no próprio "livro de Baumgarten não designa nenhuma teoria da arte. Designa o domínio do conhecimento sensível, do conhecimento claro mais ainda confuso que se opõe ao conhecimento claro e distinto da lógica" (RANCIÈRE, 2009, p. 12). 


\section{COMPOSIÇÃO METODOLÓGICA}

O método é a principal estratégia de conhecimento e experiência com o campo e, simultaneamente, é produto dele. Nas palavras de Vygotsky (1984, p. 74), “o método é, ao mesmo tempo, pré-requisito e produto, o instrumento e o resultado do estudo". Um dos arranjos deste processo de investigação consistiu na proposta de um diálogo de pesquisa entre autores da Psicologia e da História, especialmente, a micro-história.

Este princípio de pesquisa que orienta o olhar do/a pesquisador/a para os aspectos indiciários, ou seja, as pistas, os sinais, os detalhes (neste caso, em nossa própria leitura/audiência do filme), foi elaborado pelo historiador italiano Carlos Ginzburg (1939-). Este historiador é um dos pioneiros da micro-história que visualiza "uma redução na escala de observação do historiador com o intuito de se perceber aspectos que, de outro modo, passariam despercebidos” (BARROS, 2007, p.169).

A partir da leitura de pistas e sinais temos a possibilidade de criar ligações entre eventos, sendo o componente narrativo, um elemento indispensável às interpretações. Sendo assim, concordamos com Góes (2000, p. 19) quando afirma em sua obra que "apesar de privilegiar o singular, não se abandona a idéia de totalidade, pois esse modelo epistemológico busca a interconexão de fenômenos, e não o indício no seu significado como conhecimento isolado". Uma das principais contribuições de Ginzburg à Psicologia foi o seu empenho em produzir uma possibilidade metodológica que vai ao encontro do sujeito. Pensando no "singular" ou no drama tecido pela trama, Ginzburg aproxima-se de Vygotsky.

Em um texto onde discute o saber indiciário, Ginzburg (1989, p. 152) observa que "o caçador teria sido o primeiro a narrar uma história porque era o único capaz de ler, nas pistas mudas (se não imperceptíveis) deixadas pela presa, uma série coerente de eventos". A relação que estabelecemos com o audiovisual passa pelo modo como a partir de uma pesquisa documental (SPINK, 1999) é possível conjecturar sobre os modos de produção da memória. O documentário acaba sendo uma forma de estender uma realidade histórica, de fazer ecoar e fazer ver relações sociais que estão ameaçadas de esquecimento. Lemos et al. (2010, p. 98) nos ajudam na associação entre "documento" e "documentário" quando escrevem que "a mutação tecnológica resultou em novos suportes documentais, como a invenção da fotografia [...] e o surgimento de outros documentos audiovisuais e mídias digitais", permitindo assim que as imagens constituam outras formas de ver e memorar histórias na atualidade. Questões como estas nortearam nossa leitura, a fim de escavar a cena pronta que nos é apresentada e encontrar suas minúcias por baixo da terra. De acordo com Lemos et al. (2010, p.95) “objetiva-se interrogar não apenas como o documento é montado, peça por peça, mas também como deve, portanto, ser alvo de problematização". 
Situando-nos no lugar de pesquisadores/espectadores, fizemo-nos também sujeitos da experiência nesta pesquisa. Deste lugar, onde buscamos as imagens que se encontram entre o sujeito e a obra, compreendemos que ao pesquisador cabe a problematização de sua condição, da sua implicação com seu objeto de estudo e o lugar desde onde está inserido na leitura e análise deste objeto. E isto, sem deixar de considerar também a produção das informações do campo. Logo, nesta “pesquisa-espectação" o que sentimos, percebemos e pensamos na recepção audiovisual, também participa deste processo de análise.

Lembramos que o nosso olhar em pesquisa foi direcionado para uma leitura psicossocial do filme, tendo como ênfase a dimensão estética e os argumentos que colaboram para uma transposição do mero conteúdo informativo sobre a ditadura militar. Esta concepção encontra ressonância em Vygotsky, para quem a educação estética não pode propor uma função para o objeto artístico. Este talvez seja um dos princípios que nos apropriamos da obra de Vygotsky, que já pelos idos de 1920, compreendia que qualquer ensino que pretende fazer da arte um meio para o entendimento da realidade, acaba por subtrair em muito a potência de uma obra de arte.

Considerando a vivência estética que participa do processo deste trabalho, a partir das contribuições de Vygotsky, intuímos a possibilidade de realizar uma investigação marcada pelo processo de espectação de um documentário. De acordo com Vygotsky (2001, p.229), a vivência estética "pressupõe a presença de três componentes: excitação, elaboração e resposta". Compreendemos assim, que o processo de espectação de uma obra (em qualquer uma das modalidades artísticas) não ocorre passivamente, mas pode incidir naquele que assiste uma abertura de pensamentos, emoções e outros processos psicológicos complexos. A pesquisa espectação, de certa forma, depende de uma relação estética.

Pessoas concretas, marcadas pelas condições sociais e históricas que as forjaram podem estabelecer relações de variadas formas com a realidade, com os outros e consigo mesmos, relações essas que podem ser prático-utilitaristas ou estéticas. Enquanto as primeiras caracterizam o plano da cotidianidade, estas últimas destacam-se na medida em que possibilitam ao sujeito descolar-se da realidade vivida e imergir em outra, mediada por novos sentidos que contribuem para o redimensionamento e re-significação do próprio viver/existir (ZANELLA, 2006, p.144).

Concordamos com Zanella (2006) na sua compreensão das relações estéticas e pensamos que a pesquisa-espectação está constituída por uma quebra do modo utilitário do olhar e de outros sentidos que participam de uma audiência. É nesta condição que assistimos o filme, ou seja, como sujeitos espectadores e, deste lugar, pesquisadores que se arriscam a criar vínculos no "entre cenas".

Situando-nos como pesquisadores/espectadores da obra objeto de estudo, atentamos muito mais para a composição das cenas, do que necessariamente para o conteúdo verbal e informativo do filme e, por estes aspectos fomos esboçando a perspectiva estética da obra e seus desdobramentos 
sensíveis: como nos depoimentos colhidos nas casas dos entrevistados, tendo ao fundo objetos pessoais que configuram um lugar de segurança e naturalidade, ao contrário do que contam que viveram na ditadura militar.

Vygotsky (1999) entre outras contribuições às temáticas em estudo neste texto, também apresentou uma discussão que colabora na compreensão do processo de espectação, quando afirmava a raríssima vivência do espectador teatral com os sentimentos da personagem. "Só parcialmente vivenciamos no teatro os sentimentos e afetos na forma em que são apresentados nas personagens, $o$ mais das vezes os vivenciamos não com, mas movidos pelos sentimentos dessas personagens". E mais adiante acrescenta: "só muito raramente sofremos com alguém, e é muito mais frequente sofrermos motivados pelo sofrimento do outro" (VYGOTSKY, 1999, p. 262).

Neste processo de análise, foram utilizados também os registros dos pesquisadoresespectadores, que puderam admirar, fazer conexões, elaborar hipóteses e perseguir sentidos. A leitura de um audiovisual requer "um tempo outro que não o da passagem" (ZANELLA, 2011, p. 97). A passagem, ou a primeira "assistida" apresentam-se como uma inundação de informações e sensações, não sendo possível dedicar-se a muitos detalhes em uma única vez.

Seguindo este caminho assistimos a obra pela primeira vez sem preocupações e sem pesquisar por detalhes a serem analisados. As próximas vezes foram vistas com um olhar mais curioso com a intenção de "ouvir menos e enxergar mais", como uma forma de envolvermo-nos com o documentário para além do verbal. Especialmente, na Psicologia temos um domínio da escuta e com isto, uma preferência pela linguagem verbal. Com o afastamento do verbal, não é pretensão nossa tornar o filme um roteiro novamente a partir de nosso olhar, mas sim buscar um caminho diferente daquele oferecido pela lógica pedagógica e pensar em possibilidades de leitura.

Cada play trouxe reflexões de uma nova cena, uma nova ideia e uma nova leitura. As releituras das obras nos oferecem uma percepção diferenciada e nos possibilitam realizar novas compreensões e conexões que não haviam sido feitas até então. As percepções acerca da obra foram registradas por cada pesquisador com o intuito de dialogar posteriormente e compartilhar as reverberações de cada espectação, bem como servir de material para a construção da análise.

\section{RESULTADOS E DISCUSSÃO}

O filme de longa metragem foi produzido e lançado em 2011 com o apoio do Sistema Municipal de Desenvolvimento pela Cultura (SIMDEC) de Joinville/SC, que é o principal fomentador de projetos artísticos e culturais da cidade. Com a direção dos irmãos Porto, esta obra nos apresenta depoimentos de ex-presos políticos, historiadores e radialistas, a fim de relembrar o regime militar na 
cidade de Joinville e região através da sensibilidade e da fala daqueles que viveram este período tão marcante para a história do país.

O documentário aborda o regime ditatorial militar no Brasil que teve duração de 25 anos compreendendo o período de 1964 a 1989, e ainda se faz presente devido ao cenário político atual e ao cinquentenário do Ato Institucional n. 5, de 13 de dezembro de 1968. Também conhecido como AI-5, realçava "a veia mais cruel da ditadura militar iniciada no Brasil” (BRASIL ESCOLA, 2018).

\section{O “RESERVADO” DO FILME DITADURA}

O título da obra - Ditadura Reservada - nos oferece uma discussão no qual "reservada" aparece de forma polissêmica. Podemos pensar esta reserva como as intimidades e particularidades que ainda não foram contadas sobre este período, principalmente por aqueles que a vivenciaram, como os entrevistados do documentário. Em algumas cenas a câmera assume a posição de espiã e de forma discreta observa as pessoas e gera um ar de mistério sem deixar claro quem está dentro e quem está fora. Este enquadramento da câmera é utilizado antes de cenas que adentram, mas não invadem como antes fizeram os militares no regime, a casa dos entrevistados para conhecer suas histórias.

Pensando nestas cenas, temos uma imagem ícone que faz parte da capa do documentário e que dificilmente será esquecida por aqueles que o assistem (imagem 01). O personagem Edgar fecha as janelas como se fosse reservar-se no conforto e segurança de sua casa, mas ao mesmo tempo, abre sua história e suas experiências para os documentaristas.

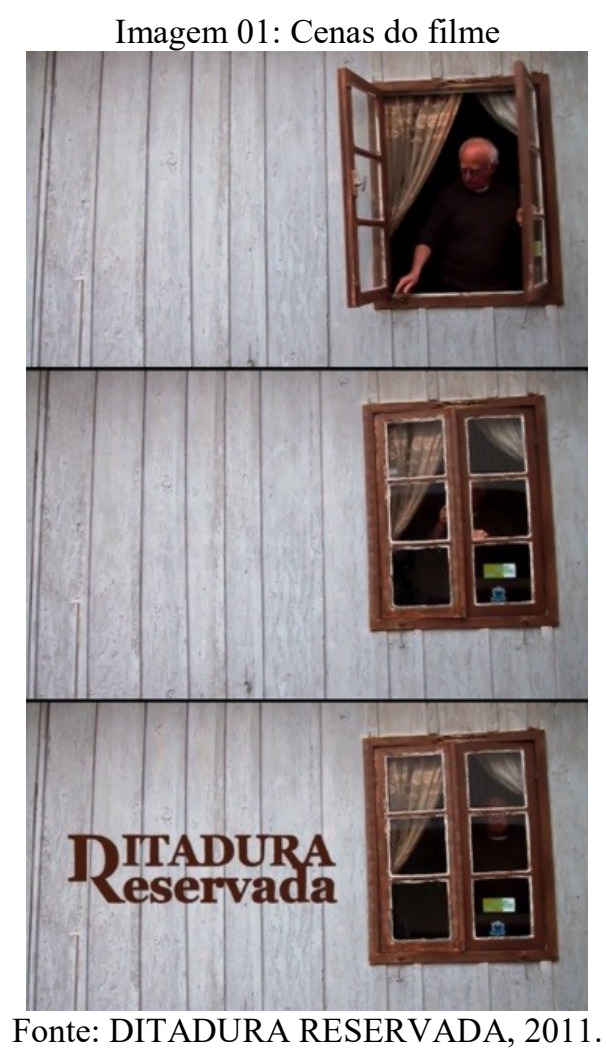


Nas primeiras cenas deste personagem, a trilha sonora acompanha seus movimentos enquanto veste uma blusa e prepara-se para receber os responsáveis pela produção da obra. O fundo musical apresenta-se de forma sedutora e convidativa aos espectadores chamando-lhes para conhecer esta história.

Edgar abre o portão de sua casa e convida a equipe envolvida na produção para entrar em seu espaço, e deste modo, aquilo que era reservado passa a ser gradualmente público. As coisas pessoais do personagem são vistas de perto, como sua estante de livros e entre eles o livro que abriga sua coleção de selos.

Em outros momentos os produtores aparecem em cena e também existem conversas entre os entrevistados e aqueles que não aparecem em frente a câmera. Pernisa Júnior e Carvalho (2017, p.38) apontam que "a relação entre documentarista e entrevistado é construída a partir das diferenças entre eles" que é possível pelo "encontro entre dois mundos socialmente diferentes e da intermediação da câmera” (FIGUEIROA et al., 2003 apud PERNISA JÚNIOR; CARVALHO, 2017, p.38).

Cenas assim não são frequentes em documentários, mas este aspecto mostra o envolvimento e a participação dos produtores e faz com que a obra assuma um caráter humanizado. Isso caracteriza o documentário na modalidade "participativa" na qual o cineasta está presente nas cenas da obra "de tal forma que leva o expectador a manter uma percepção da experiência do próprio cineasta" (OLIVEIRA; MARQUES, 2016, p. 04).

Esta humanização é percebida na forma como os depoimentos foram colhidos, através do qual as entrevistas não aparecem como interrogatórios (como aqueles feitos na delegacia durante a ditadura), mas sim com um bate papo acompanhado de uma cuia de chimarrão e o canto de pássaros ao fundo. É como se houvesse uma tentativa de restauração das vidas que foram marcadas pela opressão anos atrás. Podem retomar aquilo que viveram sem temer a prisão e sem ter que olhar para trás para ver se estão sendo vigiados. A vigia existe, mas é uma vigia permissiva e compreensiva - a câmera. Neste momento de vigia, o tempo e o espaço são exclusivos dele. Pode relembrar suas vivências e também sentir as emoções que acompanham estas lembranças sem ter uma finalidade específica. O personagem Edgar também prestou seus depoimentos neste ano em outro cenário e com outras intenções em uma audiência da Comissão da Verdade. Nesta ocasião, o relato aparece em forma de denúncia e não é acompanhado pela mesma leveza que aparenta ter encontrado frente à câmera.

No dia 26 de junho de 2014 foi criada por lei a Comissão da Verdade de Joinville, sendo a única lei, até o momento, a nível municipal no estado de Santa Catarina. A partir da escuta de perseguidos políticos, a Comissão visa resgatar e relatar casos de violação dos direitos humanos ocorridos durante a Ditadura Militar em Joinville. As audiências suscitadas pela Comissão e os 
eventos organizados na cidade para debater o assunto, colaboram com o cenário nacional que está envolvido no resgate histórico e que tem a Ditadura como foco. Os componentes representam os poderes Executivo e Legislativo, a Ordem dos Advogados do Brasil (OAB), instituições de ensino superior e entidades envolvidas com a defesa dos direitos humanos.

Outra tomada de cenas que apresenta uma situação diferente daquela vivida na ditadura referese ao encontro de ex-presos políticos que aconteceu em Curitiba. Cumprimentam-se e reúnem-se para um bate papo, mas desta vez a conversa não tem como finalidade discutir o socialismo como faziam anteriormente.

Ainda pensando sobre o olhar de humanização, os outros depoentes também aparecem em primeiro plano em cenários particulares, composto por coisas pessoais como fotografias de família, livros, máquina de escrever que representa a profissão, computador, entre outros objetos pessoais que constituem as suas personalidades.

Este olhar atento às coisas pessoais nos faz lembrar do texto "A estética da delicadeza nas roças de Minas" de Gusmão, Jobim e Souza (2008) que realizaram uma pesquisa num povoado mineiro utilizando a fotografia como ferramenta. O olhar para estas fotografias e para quem as produziu, constitui uma delicadeza estética, sendo que o tempo da delicadeza pode ser entendido como aquele em que "vislumbramos o futuro no presente, de olhos dados com o passado. [...] é também um tempo de escuta, ou melhor, de sermos testemunhas de experiências que se não forem ouvidas poderão ficar para sempre emudecidas" (GUSMÃO; JOBIM E SOUZA, 2008, p.30). Este tempo que também produz memórias "possibilita a renúncia ao assujeitamento, ao conformismo diante do risco do desaparecimento da memória" (idem), assim como as memórias dos entrevistados no documentário.

Rancière (1996) compreende a estética como realidade própria da configuração dos modos de perceber, pensar e agir no mundo e, portanto, ordenadora das relações sociais. Logo, afirmar a presença estética não qualifica uma relação, um objeto, uma intervenção, etc. porque não diz respeito a qualquer forma do "belo" ou modalidade de expressão artística. A estética é propriedade constitutiva das formas de vida humana. Diz daquilo que se essencializa nos modos de ser de uma comunidade, ou melhor, trata-se do próprio senso comum (sensorium partilhado). A estética diz respeito à “distribuição do sensível, em que são determinados os modos de articulação entre formas de ação, produção, percepção e pensamento" (PALLAMIN, 2010, p. 06).

Com a preocupação de salvaguardar o conceito dos efeitos de uma época, Rancière recupera a compreensão kantiana de que a estética vai "além da arte". Nas palavras do filósofo, estética diz respeito a "um modo de articulação entre maneiras de fazer, formas de visibilidade dessas maneiras 
de fazer e modos de pensabilidade de suas relações, implicando uma determinada ideia de afetividade do pensamento" (RANCIÈRE, 2005, p.13).

Considerando a integralidade da obra de Jacques Rancière é compreensivo o esforço teórico do pensador em não deixar escapar o sentido etimológico de estética. A primeira operação a ser feita nesta direção é deslocar a dimensão estética de sua fusão com o campo restrito da Arte, compreendendo que ela não está coligada a "filosofia ou a ciência do belo" e, que justamente por esta dissociação, sua relação com a política não diz respeito a estetização do poder, ou ainda, no estudo em questão, a estetização da memória.

\section{A PRODUÇÃO DE MEMÓRIAS DA DITADURA}

A ditadura militar foi um regime político situado historicamente, mas que ainda reverbera nas discussões da cidade de Joinville. Não é gratuito que as primeiras cenas de "Ditadura Reservada" se abastecem deste modo antagônico pelo qual as pessoas se relacionam com este tempo do Brasil. Os folhetos de campanha política espalhados pelo chão, hoje muito comum em anos eleitorais passam até mesmo despercebidos por nossos olhos. No período ditatorial esta era uma prática impensável e passível de punição.

A afirmação inicial "As opiniões cedidas para este documentário foram colhidas de forma livre e democrática" contrasta com o que acontecia na ditadura, na qual as pessoas eram coagidas a falar, algumas até sob formas variadas de tortura, e ao mesmo tempo não se tinha o direito de expressar pensamentos que divergiam da linha de pensamento político em vigor.

Os depoimentos apresentados logo no início distinguem-se em três categorias. A primeira corresponde a uma visão negativa do regime militar; a segunda corresponde a uma visão positiva; e a terceira representa formas de compreensão política contemporânea. As duas primeiras categorias contam com apenas um depoimento cada, ao contrário da terceira que tem um número elevado de contribuintes. Este elemento nos faz pensar sobre as intenções do documentário e que ficam claras no decorrer das cenas, isto é, levantar um olhar que se tem do presente em relação ao passado e para isso não seguir uma linha cronológica.

A visão da micro-história é reforçada ao apresentar heróis políticos, e não nos referimos a Lenin ou Che Guevara. Edgar fala com emoção ao descrever estes dois personagens acompanhado de um quadro de fundo com a imagem de Lenin, mas possivelmente sem se dar conta de que ele mesmo é um herói (imagem 02). Ao mesmo tempo em que acompanhamos a fala e o movimento do personagem, somos vigiados pelo olhar emblemático de Lenin. 


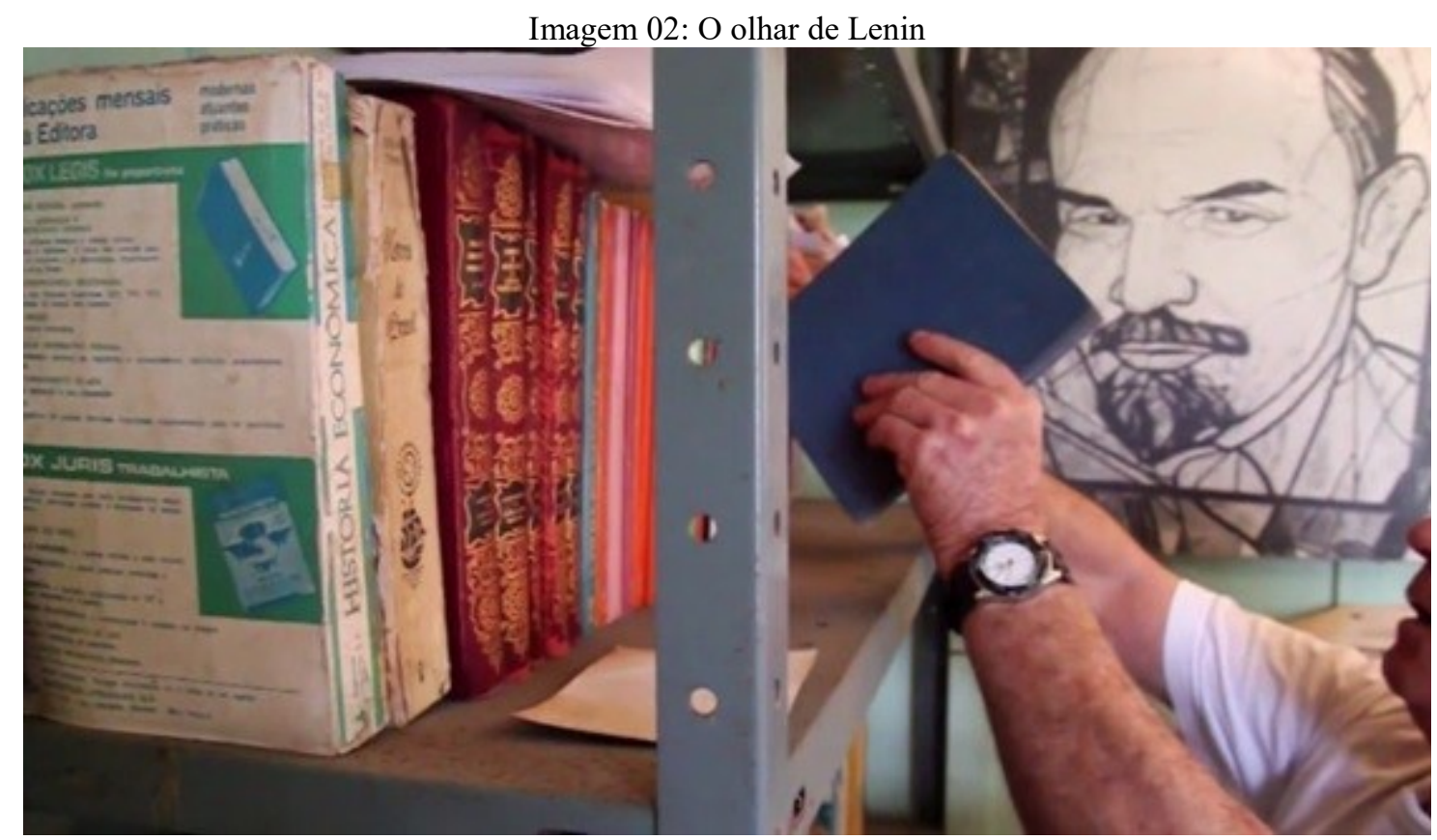

Fonte: DITADURA RESERVADA, 2011.

Enquanto pronuncia as últimas palavras sobre seus ídolos, a música acompanha a troca de cenas dando entrada ao relato da primeira prisão de Edgar, o que caracteriza uma aproximação de heróis que fazem parte da história e são produtores de memória.

A memória não é um processo que se oficializa, portanto vive em constante movimento assim como as cenas que compõem o enredo de uma produção audiovisual. Este movimento de memória e de cenas é o que nos permite a análise, pois "é somente em movimento que um corpo mostra o que é" (VYGOTSKY, 1984, p.74).

De acordo com Berger e Chaves (2009, p.30) a produção da memória da ditadura no Brasil

se inscreve no movimento internacional que recorda traumas nacionais; ela conta, para a sua produção, com os relatos das testemunhas da época; ela acontece na mídia ou através dos suportes midiáticos disponíveis e carrega as ambiguidades da triangulação entre lembrar, esquecer e narrar. E deixa suspensa a pergunta sobre as possibilidades de a cultura produzida nos suportes midiáticos iluminar e esclarecer o acontecido.

Os relatos de testemunhas são confrontados quando temos dois extremos presentes, isto é, os protagonistas-testemunhas e os militares. Por mais que Ditatura Reservada não aborde o discurso de militares, apresenta visões opostas e este encontro entre elas provoca "uma disputa de sentidos que vai além do discurso" (BERGER; CHAVES, 2009, p.31), e apesar de possíveis efeitos desejados, cabe ao espectador interpretá-las.

Ditadura Reservada (2011) movimenta-se de uma forma que parece nadar contra a corrente de produção de memórias da ditadura, pois muitas obras apresentam um aspecto pesado, marcado pela violência e pelas torturas. Aqui o diretor olha por trás das cortinas, ou por baixo do tapete, e 
direciona seu olhar para aquilo que não ganhou destaque, isto é, as experiências individuais com este período. Por tratar de histórias individuais, permite a exploração de sentidos e sentimentos únicos com uma enorme capacidade de afetação ao acompanharmos a história de alguém e sentir como ele sentiu, ou tentar aproximar-se disto. Com isso, a obra transita pelo registro estético, também conhecido como democrático, ao distanciar-se dos personagens "oficiais" ou emblemáticos da militância deste período, projetando, assim, na superfície plana a vida do sujeito anônimo (RANCIÈRE, 2009).

Ao analisarmos uma obra devemos levar em conta aquilo "que diz respeito ao conteúdo e à linguagem particulares de cada filme, ou seja, a sequência dos acontecimentos que compõem a história do filme da maneira como são contados e articulados entre si” (DAVID; HAUTEQUESTT; KASTRUP, 2012, p. 133). A experiência de assistir uma produção audiovisual "envolve um mergulho da atenção nas imagens visuais e auditivas que o filme oferece, e um deixar-se conduzir pela história, pelos personagens e pelas emoções” (IDEM, p.128). Este envolvimento ganha força quando temos a possibilidade de acompanhar o trajeto da câmera, como nas cenas em que assume papel de espiã.

Os entrevistados têm seus depoimentos colhidos em suas casas, em um ambiente que lhes proporciona segurança e liberdade, mas sabemos que nem sempre foi assim. Através dos discursos percebemos que estar em casa naquela época não representava proteção, pois os militares os investigavam e invadiam suas casas para realizar prisões, muitas vezes sem uma queixa clara. $\mathrm{O}$ governo contava com espiões que auxiliavam as investigações e agilizavam as prisões de pessoas suspeitas por estarem a favor do comunismo.

A ditadura não é o primeiro momento de perseguição à população na história de Joinville, já vimos esta cena antes quando aconteceu a Campanha de Nacionalização que atingiu todos os grupos descendentes de imigrantes. O período da Segunda Guerra Mundial (1939-1945) corresponde à fase de maior repressão vivida pela Campanha que buscava o "abrasileiramento" da população. A partir de 1939 todas as publicações feitas em línguas estrangeiras foram proibidas e algumas escolas passaram a ser fechadas por usarem a língua alemã (SEYFERTH, 1994). Neste cenário, as pessoas também eram vigiadas em suas próprias casas e deveriam tomar cuidado ao comunicarem-se utilizando sua língua materna, pois o simples falar tornou-se motivo para acusação e aprisionamento. A população encontrou formas para desviar os olhos dos espiões e militares que os controlavam. Era comum que realizassem reuniões em pequenos grupos para estudar e discutir a política e outros assuntos na língua alemã.

Para a produção desta obra audiovisual realizou-se uma pesquisa histórica para contextualizar e situar o período ditatorial. Percebe-se que há um cuidado com a história e não somente o interesse em apresentar novas fontes - os discursos dos entrevistados. No decorrer do longa algumas 
informações são apresentadas para situar o espectador, como a data das eleições que aparecem no início, as prisões de Edgar, a data do encontro de ex-presos políticos, entre outros. Estas notas aparecem mais como uma localização cronológica do que uma explicação dos eventos que marcaram os anos de ditadura, visto que não apresenta esclarecimentos sobre o que foi este período, sobre o que era comunismo, socialismo, entre outros conceitos importantes para uma compreensão ampliada deste momento político para o país.

O diretor trabalha com uma economia dos sentidos, através da qual busca lançar os acontecimentos e convidar os espectadores para que organizem a história de sua maneira. Ele não resolve a trama e nem mastiga os fatos de modo com que a digestão da obra seja facilitada ao espectador. Pensando desta forma, entendemos que o diretor faz o papel de dirigir a câmera e o olhar do espectador, mas não pode conduzir o sentido que o espectador produzirá no intervalo de cenas. Vygotsky (2001) apresenta um texto intitulado “A educação estética” onde analisa o uso de fábulas infantis e sua função moral, concluindo que "nunca podemos ter certeza antecipadamente de qual será a influência moral de um determinado livro" (VTGOTSKY, 2001, p.226).

Assim como acontece com as fábulas (e suas intenções morais), acontece também com as produções audiovisuais. O diretor apresenta uma ideia e espera algo do espectador, mas não pode garantir que este será o resultado, pois o espectador é sujeito situado sócio historicamente, sujeito de paixões e experiências, que influenciam na capacidade de afetação do filme.

\section{O PESQUISADOR/ESPECTADOR NAS FRONTEIRAS DA PSICOLOGIA, HISTÓRIA E CINEMA}

Além da pesquisa histórica, o gênero documentário utiliza-se de outras ferramentas, dentre elas a história oral que é "um método de pesquisa que privilegia a realização de entrevistas com pessoas que participaram de, ou testemunharam, acontecimentos, conjunturas, visões de mundo, como forma de se aproximar do objeto de estudo" (ALBERTI, 2005, p.18). Os depoimentos são utilizados desde o tempo de Heródoto e Tucídides, os quais utilizavam relatos para dar forma às suas narrativas, mas devido a inexistência de gravadores não podiam transforma-los em documentos para consulta posterior.

Assim podemos compreender a história oral, como uma "ciência e arte do indivíduo" (PORTELLI, 1997, p.15) que através de conversas sobre experiências, busca as memórias individuais e os impactos que causam na vida das pessoas. Pensamos esta ciência representada no documentário pela história de vida de Edgar, uma vida sofrida que gera uma sensibilidade no filme através do ato de testemunhar aquilo que viveu. Aqui a história oral desloca-se de um lugar "acadêmico" para o 
campo do comum, das relações comunitárias e citadinas, não caindo em um movimento que abrange apenas a ciência e a História. A história oral não permite apenas o contar, mas também traz a experiência do que os entrevistados vivenciaram. A experiência de cada um é única, o que eles experimentaram, ninguém mais experimentou.

Segundo Benjamin (1993), vivemos em uma escassez da experiência. Este empobrecimento da experiência deve-se, entre outros motivos, a mudança que sentimos em relação ao ritmo do tempo. Na vida urbana vivencia-se o tempo aceleradamente, a velocidade do dia está associada ao tempo da produção, dos prazos, da informação. Esta aceleração do tempo soa "como se estivéssemos privados de uma faculdade que nos parecia segura e inalienável: a faculdade de intercambiar experiências" (BENJAMIN, 1994, p. 198). Este intercâmbio é concretizado através do narrar, sendo que a história se gravará na memória do ouvinte/espectador mais facilmente na medida em que o narrador renuncia às sutilizas psicológicas com maior naturalidade. Assim "mais completamente ela se assimilará [a história] à sua própria experiência e mais irresistivelmente ele cederá à inclinação de recontá-la um dia” (BENJAMIN, 1994, p. 204).

A narrativa alimenta-se do cotidiano em busca de experiência e encontra forças para isso através do encontro entre o audiovisual e a história oral. Esta noção de história oral, como ciência e arte do indivíduo, constitui um ponto fundamental de encontro entre a Psicologia, a História e o Cinema. Com contribuições específicas de cada área citada temos uma combinação de elementos que constituem a obra, como a atenção à história de cada um, a performance narrativa, expressões faciais, gestos e entonações que estão registrados e podem ser vistos quantas vezes for desejado.

Temos uma cena que nos mostra a sensibilidade da câmera/diretor ao captar as palavras de Lúcia sobre o reencontro com seu marido Edgar após um período de desaparecimento. O close feito pela câmera em seu rosto nos faz sentir a emoção do momento e até mesmo imaginá-lo. O tom de voz utilizado pela personagem caracteriza uma memória de sofrimento, que se constitui como elemento sensível participante da estética, assim como a história de vida do marido. As pausas em sua fala dançam no mesmo compasso em que suas expressões faciais se movimentam, apresentando assim uma sintonia entre estes elementos e que se mostram como aspectos de realidade em sua história.

A combinação entre as áreas da psicologia, história e cinema, tornam possível a análise deste "entre cenas" que constitui a pesquisa. A psicologia entra em cena na análise devido à sua relação com sentimentos e a compreensão do indivíduo, que se relaciona fortemente com o que é proposto pela história oral. A história oral possibilita uma relação pessoal e dual, entre o entrevistado e a câmera. Esta relação entre as duas áreas se fortalece com a entrada do cinema, o qual tem o controle 
de escolha do lugar da câmera e também tem a chance de criar um público para mostrar as possibilidades de criações desenvolvidas entre as áreas citadas.

Outro elemento utilizado pelo documentário está entre as trocas de cenas. Muitas vezes são utilizadas imagens de recortes de jornais ou fotografias antigas em um tom de envelhecimento que contrastam com as cores contidas nas cenas de depoimentos. Para Mauad (2005, p.35) "a fotografia [...] é um discurso feito a partir da realidade" e ao ser inserida no documentário, pode provocar perturbações em quem assiste a esta construção narrativa (BUITONI, 2008).

A separação de cores funciona como uma demarcação do passado e do presente, mas que não é tão simples assim a nível psicológico. De acordo com Freitas (2016, s/p) "na teoria do audiovisual, [...] cores são um elemento eficaz na comunicação de emoções subjetivas para a audiência. A base é a teoria das cores, que sugere que cores e tons são capazes de influenciar ou comunicar certos espectros de emoções”. As imagens são uma lembrança, uma representação de algo que já aconteceu na vida dos entrevistados, mas que é marcada por muita vivacidade no discurso dos mesmos.

Carrière (1995, p. 21) afirma que todas as formas de expressão, sejam elas pictóricas, teatrais ou meramente sociais, vivem de "memórias reconhecidas ou não reconhecidas, uma fonte de conhecimentos, pública ou privada, que brilha com maior intensidade para alguns e com menor para outros". O cinema tem participação importante nas formas de expressão e sentimentos, "inventou modos de falar, êxtases, aflições, novos tipos de terror. Pode até ter nos ajudado a descobrir em nós mesmos sentimentos até então desconhecidos" (CARRIÈRE, 1995, p.34) e que são exaltados ao nos envolvermos com a história apresentada.

Experimentamos uma mistura de sentimentos quando o casal protagonista, Lucia e Edgar, visitam o Arquivo Público do Paraná localizado em Curitiba onde revivem algumas memórias ao encontrarem fotos de pessoas desaparecidas e ao analisar arquivos que contém informações das prisões de Edgar. Algumas fotos dele também reforçam as memórias que o passado não deixa esquecer.

Em seu texto "Imagens do passado: noções e usos contemporâneos", Gervaiseau (2012) aborda questões relacionadas ao holocausto da Segunda Guerra Mundial e o extermínio em Auschwitz que também teve resistentes ao movimento. Assim como aqueles que vivenciaram a ditadura no Brasil, esta resistência “identificava-se com a possibilidade de manter uma imagem de si, de preservar o seu eu, no sentido psíquico e social do termo, com a possibilidade de permanecer de pé, marchar ereto, ou seja, não virar [...] submerso, homem próximo ao fim” (GERVAISEAU, 2012, p.214).

A sequência de depoimentos e informações vai nos dando ideias e situações diferentes, sem demonstrar intenção aparente de afirmar uma verdade ou superioridade de uma história em relação à 
outra. Esta organização nos faz pensar na ideia de espectador que os produtores têm, um espectador que pode entrar em contato com as cenas e processá-las a partir dele mesmo, sem necessitar de uma verdade concebida previamente, um espectador que faz suas próprias interpretações.

Por muito tempo cultivou-se no campo da ciência psicológica a ideia de que "o critério de que a percepção estética constitui uma vivência totalmente passiva, uma total entrega à impressão, uma detenção de toda a atividade do organismo" (VYGOTSKY, 2001, p. 229). Aqui compreendemos que a espectação é um processo psicológico complexo, polissêmico, dialógico, com possibilidades de múltiplos pensamentos, inclusive, no plano da memória. Nesta perspectiva, a passividade total frente a uma obra torna-se impensável a partir do momento em que compreendemos que a análise audiovisual é uma atividade complexa, e que a visão e a audição são apenas o impulso básico.

O pesquisador/espectador necessita envolver-se com a obra para poder senti-la, do contrário, a leitura audiovisual pode ficar impossibilitada "justamente pela dificuldade de acesso às cifras que permitem a transposição do sentido figurado ao próprio" (RAFFAELLI, 2004, p.213). Neste sentido, a pesquisa espectação também se aproxima do paradigma indiciário, pois diante da gama de signos que constitui uma obra, o pesquisador ao se debruçar nas pistas e detalhes da obra, expõem-se pelas suas escolhas, indicando pelos detalhes que analisa a sua perspectiva de audiência. Desta forma, fazemos nossas as palavras de Rodrigues (2005, p.06), pensando que a pesquisa espectação "valoriza a aproximação emocional do observador com o seu objeto, os traços e o conhecimento individuais em detrimento à generalização".

Destacamos no documentário o depoimento de Rosimarie, ex-presa política que atuava como assistente social na época da ditadura, ao falar sobre sua prisão na qual sofreu torturas de choque e também o envolvimento de seu irmão e sua mãe. A emoção aparece por apresentar um elemento comum a nós, a família, o que possibilita que nos aproximemos da dor e das lembranças da entrevistada. A partir deste depoimento "somos levados a nos indagar sobre os efeitos desta violência não elaborada, não só em termos individuais, como também comunitários, ainda que décadas de abertura política rumo à democratização tenham se passado" (GOLDSTEIN, 2013, p.513). O cenário político mudou, a vida destas pessoas mudou, mas as marcas deixadas continuam sem compreensão ou elaboração.

A história tem como fio condutor a relação do casal protagonista Lúcia e Edgar, o que primeiramente nos faz pensar em uma romantização da ditadura através da história de pessoas que se conheceram e se uniram neste período. Ao analisarmos a disposição dos depoimentos do casal, nos damos conta de que aparecem separadamente durante grande parte do longa-metragem. Esta separação remonta ao regime militar no qual o casal sofreu várias separações devido às prisões de Edgar. Uma cena que reforça esta ideia, é a cena em que Edgar aparece na parte externa de sua casa 
arrumando a casa dos passarinhos, e enquanto ele age a voz de Lúcia pode ser ouvida, afirmando que a esposa sempre acompanhou seus passos e sua história.

Nas partes finais o diretor mostra-se um tanto generoso através da fala de Lucia sobre a juventude. O saudosismo presente em seu discurso, nos faz pensar sobre as vantagens do movimento de resistência feito na ditadura e do que representaria hoje. A queixa da personagem sobre a acomodação dos jovens soa como um convite aos mesmos, para uma vida de resistência, assim como foi a dela.

O diretor revela parte de suas intenções que foram escondidas em outros momentos do filme, como quando exibe a sequência de depoimentos que oferecem pareceres sobre a ditadura militar em Joinville. Estes pareceres são pontos de vista de pessoas como Nilson Bender, ex-prefeito de Joinville, a historiadora Sirlei de Souza, o ex-vereador Ulisses Tavares Lopes e o radialista José Eli Francisco. Esta contraposição de depoimentos e pareceres, sugestiona uma tentativa de situar o diretor em campo neutro, assim como suas intenções. Esta contraposição pode passar despercebida, pois as informações já nos chegam explicadas, enquanto que "metade da arte narrativa está em evitar explicações" (BENJAMIN, 1993, p. 203). Não há quem possa articular e compreender integralmente tanta novidade sobre tudo, e isso muitas vezes nos coloca em uma posição de espectadores passivos.

\section{CONSIDERAÇÕES FINAIS}

Ditadura Reservada (2011) não se esgota no relato verbal, mas apesar do predomínio dos depoimentos, transmite mais do que informações, convocando o espectador a participar de memórias e experiências que ultrapassam o comum das opiniões sobre o regime militar. Este olhar nos possibilitou uma aproximação sensível com as histórias de vida destes sujeitos do documentário, bem como, com as questões de época no contexto local.

Sem perder de vista o contexto histórico da ditadura militar, a investigação foi direcionada para uma possibilidade de rompimento com aquela forma de comunicação imediata e cotidiana, tão conhecida na contemporaneidade: a informação. Compreendemos que o tempo da pesquisa foi um tempo de experiência. Sentimos a leitura audiovisual como uma tarefa que exige do pesquisador/espectador não somente o envolvimento com a obra, mas também uma dose de sensibilidade que facilita a entrada do olhar curioso no "entre cenas" buscando encontrar coisas que não estão prontamente identificadas. As relações estéticas abordadas aqui, sustentadas conceitualmente na obra de Jacques Rancière e Lev S. Vygotsky, compõem uma possibilidade de investigação na Psicologia Social. 
A estética como parte da composição metodológica oportunizou analisar o impacto da obra de arte escolhida sobre aqueles que assistem, a partir dos pensamentos, emoções e outros processos psicológicos complexos. Os detalhes que compõem uma obra audiovisual não são inocentes, muitas vezes são pensados com uma finalidade específica, mas que não é garantida ao espectador. Por sua vez, o espectador fará suas análises a partir de suas experiências e seus referenciais.

\section{REFERÊNCIAS}

ALBERTI, Verena. Manual de História Oral. $3^{\text {a }}$ ed. Rio de Janeiro: FGV, 2005.

ALVES, Laura Maria Silva Araújo. O cinema como fonte investigativa para compreensão da infância: o uso de recursos audiovisuais no ensino de psicologia. Revista de Geografia e Interdisciplinaridade, v.3, n.11, p.35-56, 2017.

BARROS, José D'Assunção. Sobre a feitura da micro-história. Revista OPSIS, v.7, n.9, p.167-185, jul./dez. 2007.

BENJAMIN, Walter. Experiência e pobreza. In: BENJAMIN, Walter. Obras escolhidas: magia e técnica, arte e política. São Paulo: Brasiliense, 1993.

BENJAMIN, Walter. O Narrador - Considerações sobre a obra de Nikolai Leskov. In: BENJAMIN, Walter. Magia e técnica, arte e política: ensaios sobre literatura e história da cultura. $7^{\mathrm{a}}$ ed. São Paulo: Brasiliense, 1994.

BERGER, Christa; CHAVES, Juliana Campos. A contribuição do cinema para a memória da ditadura brasileira. Comunicação \& Educação, Ano XIV, n.3, set./dez. 2009.

BRASIL ESCOLA. 50 anos do AI-5 e a intervenção militar no Rio de Janeiro. Disponível em: https://vestibular.brasilescola.uol.com.br/atualidades/50-anos-ai5-intervencao-militar-no-riojaneiro.htm. Acesso em: 18 de outubro de 2018.

BUITONI, Dulcília Helena Schroeder. Fotografia e Documentário: a inovação pode estar no passado. Intercom - Sociedade Brasileira de Estudos Interdisciplinares da Comunicação - XXI Congresso Brasileiro de Ciências da Comunicação, Natal, 2008.

CABRAL, Marcelo Grimm. Eisenstein e a Psicologia da Arte. 2008. 206f. Dissertação de Mestrado em Psicologia - Universidade Federal de Santa Catarina, Florianópolis.

CARRIÈRE, Jean-Claude. A linguagem secreta do cinema. Rio de Janeiro: Nova Fronteira, 1995. 
COELHO, Ilanil. Pelas Tramas de Uma Cidade Migrante. Joinville: Ed. Univille, 2011.

DAVID, Jéssica; HAUTEQUESTT, Felipe; KASTRUP, Virginia. Audiodescrição de filmes: experiência, objetividade e acessibilidade cultural. Fractal Revista de Psicologia, v.24, n.1, p.125142, abr. 2012.

DITADURA reservada. Direção: Fabrício Porto. Produção: Sabrina Elisa. Roteiro: Fabrício Porto. Joinville: Guarda Filmes, 2011. 1 filme (79 min), DVD, son., color., 16:9.

FREITAS, Ana. Como as paletas de cores determinam o clima dos filmes. 2016. Disponível em: https://www.nexojornal.com.br/expresso/2016/05/27/Como-as-paletas-de-cores-determinam-oclima-dos-filmes. Acesso em: 27 out. 2018.

GERVAISEAU, Henri Arraes. Imagens do Passado: noções e usos contemporâneos. In: MORETTIN, Eduardo; NAPOLITANO, Marcos; KORNIS, Mônica (Orgs.). História e Documentário. Rio de Janeiro: FGV, 2012.

GINZBURG, Carlos. Mitos, emblemas, sinais: morfologia e história. São Paulo: Cia. das Letras, 1989.

GÓES, Maria Cecília Rafael. A abordagem microgenética na matriz histórico-cultural: Uma perspectiva para o estudo da constituição da subjetividade. Cadernos Cedes, ano $\mathrm{XX}, \mathrm{n}^{\circ}$ 50, Abril/2000.

GOLDSTEIN, Thaís Seltzer. Trauma, memória e justiça em "a morte e a donzela", de Roman Polanski. Psicologia USP, São Paulo, v.24, n.3, p. 509-526, 2013.

GOMES, Allan Henrique; PASQUALOTTO, Mariana Zabot; BAPTISTA, Lilian Vegini. A loucura na cidade de Joinville no século XX: o paradigma indiciário como proposta metodológica de pesquisa em psicologia. Revista Confluências Culturais, v.5, n.1, p.81-95, mar. 2016.

GUSMÃO, Denise Sampaio; JOBIM E SOUZA, Solange. A estética da delicadeza nas roças de Minas: sobre a memória e a fotografia como estratégia de pesquisa-intervenção. Psicologia \& Sociedade, v.20, Ed.Especial, p. 24-31, 2008.

GUTFREIND, Cristiane Freitas; RECH, Nathalia Silveira. A Memória em construção: a ditadura militar em documentários contemporâneos. Em Questão, Porto Alegre, v. 17, n. 2, p. 133-146, jul./dez. 2011. 
IBGE. Joinville. 2018. Disponível em: https://cidades.ibge.gov.br/brasil/sc/joinville/panorama. Acesso em: 24 out. 2018.

JOBIM E SOUZA, Solange. A Pesquisa em ciências humanas como intervenção nas práticas do olhar. In: Da Ros, Silvia Zanatta. Lenzi, Lucia Helena Correa; Slazzaouza, Ana Maria Alves; Gonçalves, Marise Matos (Orgs.). Imagem: intervenção e pesquisa. Florianópolis: UFSC, 2006.

LEMOS, Flávia Cristina Silveira et al. A análise documental como instrumento estratégico para Michel Foucault. In: PIMENTEL, Adelma e Cols. (Org). Itinerários de pesquisa em Psicologia. Belém: Amazônia, 2010.

LOPES, Maria do Socorro Vieira et al. O cinema como ferramenta transformadora do ensino em saúde: relato de experiência. Revista Saúde \& Ciência, v.6, n.3, p. 106-116, 2017.

MAUAD, Ana Maria. Na mira do olhar: um exercício de análise da fotografia nas revistas ilustradas cariocas, na primeira metade do século XX. Annals of Museu Paulista, v.13, n.1, jan./jun. 2005.

OLIVEIRA, Michelle Gusmão; MARQUES, Edmilson Ferreira. O documentário e suas especificidades. III Congresso de Ensino, Pesquisa e Extensão da UEG. Inovação: inclusão social e direitos. Pirenópolis - Goiás, outubro 2016.

PALLAMIN, Vera. Aspectos da relação entre o estético e o político em Jacques Rancière. In: RISCO, Revista de Pesquisa em Arquitetura e Urbanismo (Online), São Carlos, n. 12, 2010.

PERNISA JÚNIOR, Carlos; CARVALHO, Helena Oliveira Teixeira. Jogo de cena: um outro olhar sobre a entrevista no documentário. Doc On-line, n. 22, p. 28-47, set. 2017.

POLLAK, Michael. Memória, esquecimento, silêncio. Estudos Históricos, Rio de Janeiro, v. 2, n. 3, 1989.

PORTELLI, Alessandro. Tentando aprender um pouquinho. Algumas reflexões sobre a ética na História Oral. Projeto História, São Paulo, v.15, p. 13-49, abr. 1997.

RAFFAELLI, Rafael. Solaris: conhecimento e autoconhecimento. Psicologia USP, v.15, n.3, p. 213$231,2004$.

RANCIÈRE, Jacques. O espectador emancipado. Urdimento, Florianópolis, n.15, p. 107-122, out. 2010a. 
RANCIÈRE, Jacques. A associação entre arte e política segundo o filósofo Jacques Rancière. Revista Cult, ed. 139, 2010b. Disponível em: http://revistacult.uol.com.br/home/2010/03/entrevista-jacquesranciere. Acesso em: 01 out. 2018.

RANCIÈRE, Jacques. O Desentendimento. Trad. Ângela Leite Lopes. São Paulo, Ed. 34, 1996.

RANCIÈRE, Jacques. A partilha do sensível. Estética e política. Tradução de Monica Costa Netto. 2. ed. São Paulo: Editora 34, 2005.

RANCIÈRE, Jacques. O inconsciente estético. São Paulo: Editora 34, 2009.

RODRIGUES, Márcia B.F. Razão e sensibilidade: reflexões em torno do paradigma indiciário. Dimensões - Revista de História da Ufes: Estado, sociedade e poder, Vitória, v. 17, 2005.

SANTEIRO, Tales Vilela; SCHUMACHER, Joice Veridiane; SOUZA, Tariana Machiavelli Carmo. Cinema e violência contra a mulher: contribuições à formação do psicólogo clínico. Temas em Psicologia, Ribeirão Preto, v.25, n.2, p.401-413, jun. 2017.

SEYFERTH, Giralda. A identidade teuto-brasileira numa perspectiva histórica. In: MAUCH, Cláudia (org.). Os alemães no sul do Brasil: cultura, etnicidade, história. Canoas: Ulbra, 1994.

SPINK, Peter Kevin. Análise de Documentos de Domínio Público In: SPINK, M. J. (org.) Práticas Discursivas e Produção de Sentidos no Cotidiano. São Paulo: Cortez, 1999. 123-152 p.

VYGOTSKY, Lev Semenovitch. Formação social da mente. São Paulo: Martins Fontes, 1984.

VYGOTSKY, Lev Semenovitch. Psicologia da Arte. São Paulo: Martins Fontes, 1999.

VYGOTSKY, Lev Semenovitch. Psicologia Pedagógica. São Paulo: Martins Fontes, 2001.

ZANELLA, Andrea Vieira. Arte(s), Tecnologia(s), Cidade(s): Processos de Sujeição e Resistências Inventivas. In: TOMANIK, E. A. e CANIATO, A. M. P. (Orgs). Psicologia Social: desafios e ações. Maringá: ABRAPSO, 2011. p.88-98.

ZANELLA, Andrea Vieira. Escrever. In: FONSECA, T. M. G. E COLS. Pesquisar na diferença: um abecedário. Porto Alegre: Sulina, 2012. 
ZANELLA, Andrea Vieira. Sobre olhos, olhares e seu processo de (re)produção. In: Da Ros, Silvia Zanatta. Lenzi, Lucia Helena Correa; Souza, Ana Maria Alves; Gonçalves, Marise Matos (Orgs.). Imagem: intervenção e pesquisa. Florianópolis: UFSC: NUP/CED/UFSC, 2006. 